\title{
Neuropeptide-Y
}

\section{A Peptide Found in Human Coronary Arteries Constricts Primarily Small Coronary Arteries To Produce Myocardial Ischemia in Dogs}

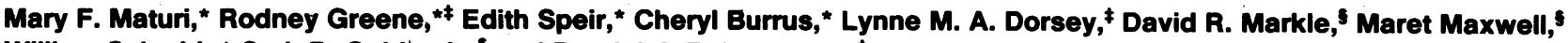 \\ William Schmidt, ${ }^{*}$ Seth R. Goldstein, ${ }^{3}$ and Randolph E. Patterson ${ }^{* *}$ \\ *Experimental Physiology and Pharmacology Section, Cardiology Branch, National Heart, Lung, and Blood Institute, and ${ }^{\S}$ Mechanical \\ Engineering Section, Biomedical Engineering and Instrumentation Branch, National Institutes of Health, Bethesda, Maryland 20892; \\ and ${ }^{\ddagger}$ Department of Medicine (Cardiology), Emory University School of Medicine, Carlyle Fraser Heart Center, \\ and Crawford Long Hospital of Emory University, Atlanta, Georgia 30365
}

\begin{abstract}
Neuropeptide-Y (NPY), a brain peptide; is located in the walls of human coronary arteries. This study assessed the effects of NPY on the coronary circulation in $\mathbf{4 0}$ chloralose-anesthetized, open-chest dogs. Intracoronary NPY (42 nmol over $5.2 \mathrm{~min}$ ) caused a $39 \%$ reduction in coronary blood flow without changing heart rate or aortic pressure. To determine whether this vasoconstriction could produce ischemia, intramyocardial $\mathbf{p H}$ was measured in seven dogs (group I) and decreased from $7.45 \pm 0.06$ to $7.37 \pm 0.06 \mathrm{pH}$ units after NPY in the subendocardium $(P<0.0002)$, and from $7.45 \pm 0.06$ to $7.40 \pm 0.05 \mathrm{pH}$ units $(P<0.04)$ in the subepicardium of the infused zone. Left ventricular ejection fraction (LVEF), measured by radionuclide angiography, decreased from $0.52 \pm 0.08$ to $0.42 \pm 0.12 \mathrm{U}$ ( $n=5, P<0.01$ ) during NPY. NPY-induced vasoconstriction was also associated with ST-T wave changes on the electrocardiogram (ECG) in eight of nine other animals (group V). In another group of six dogs (group IV), the change in small vessel resistance accounted for $94 \%$ of the increase in total resistance, so that the primary vasoconstrictor effect of NPY was exerted on small coronary arteries. Thus, NPY, a peptide found in human coronary arteries, caused constriction of primarily small coronary arteries that was severe enough to produce myocardial ischemia as determined by ECG ST-T wave changes, and decreases in intramyocardial pH and LVEF in dogs.
\end{abstract}

\section{Introduction}

Neuropeptide-Y (NPY) ${ }^{1}$ was isolated from porcine brain in 1982 (1), and it has been found in high concentrations in

Address correspondence to Dr. Randolph E. Patterson, Carlyle Fraser Heart Center at Crawford Long Hospital of Emory University, 550 Peachtree Street, Room 4323, Atlanta, GA 30365.

Received for publication 26 June 1984 and in revised form 11 November 1988 .

1. Abbreviations used in this paper: $\mathrm{AP}$, aortic pressure; $\mathrm{CBF}$, coronary blood flow; DCP, distal coronary pressure; LVEF, left ventricular ejection fraction; NPY, neuropeptide-Y; $R_{L}$, large coronary artery resistance; $\mathbf{R}_{\mathbf{S}}$, small coronary artery resistance.

J. Clin. Invest.

(c) The American Society for Clinical Investigation, Inc.

0021-9738/89/04/1217/08 \$2.00

Volume 83, April 1989, 1217-1224 human coronary arteries (2). There are, however, few studies defining the physiological effects of NPY. In feline studies NPY caused vasoconstriction in the submandibular gland and increased systemic arterial pressure (3). The effects of NPY on the coronary circulation have not been previously studied. The purpose of the present study was, first, to test the hypothesis that NPY can cause vasoconstriction of coronary arteries. To evaluate this, we measured the effects of NPY on coronary blood flow (CBF) and coronary vascular resistance. Second, we tested the hypothesis that NPY-induced coronary vasoconstriction was severe enough to cause myocardial ischemia. To evaluate ischemia we measured intramyocardial $\mathrm{pH}$. As two independent lines of evidence of ischemia, left ventricular ejection fraction (LVEF) and the ST-T waves of the electrocardiogram (ECG) were recorded to confirm independently whether ischemia occurred and to determine the functional significance of any ischemia. Further, if this peptide could produce such intense coronary vasoconstriction that it could overcome endogenous coronary regulation, it would be important to know whether NPY acted on large coronary arteries (remote from the small vessels where normal regulation occurs) or directly at the level of small vessels. Thus, to determine the site of action of NPY, we also measured the resistances of large $\left(R_{L}\right)$ and small $\left(R_{s}\right)$ coronary arteries using the differential pressure measurements described by Fam and McGregor (4).

\section{Methods}

40 foxhound dogs weighing $25-35 \mathrm{~kg}$ were anesthetized with $3 \mathrm{mg} / \mathrm{kg}$ i.m. morphine sulfate and $100 \mathrm{mg} / \mathrm{kg}$ i.v. alpha chloralose (bolus), then maintained on a 3-8-mg/ $\mathrm{kg}$ per $\mathrm{h}$ infusion of chloralose in normal saline. A left thoracotomy was performed and a pericardial cradle was constructed.

A 1-2-cm segment of the left circumflex or left anterior descending coronary artery was isolated to place an electromagnetic flow probe (Carolina Medical Electronics, Inc., King, NC) proximal to a pneumatic occluder (R. E. Jones Co., Silver Spring, MD) on the coronary artery. Preliminary results showed no difference in the response to NPY between these two branches of the left coronary artery. The pneumatic occluder was used to stop flow momentarily to check the balance of the flow probes that were previously calibrated in blood. A 22-gauge catheter was inserted retrograde for infusion into the same proximal coronary artery. Aortic pressure (AP) was monitored through a femoral arterial catheter registering both mean and phasic signals via two carefully balanced and calibrated pressure transducers. Arterial blood gases were monitored periodically and maintained within normal limits by adjusting ventilation. 
To evaluate the effect of NPY on the coronary circulation, CBF, heart rate, and $A P$ were measured in all dogs during the basal state and after NPY at the time of the peak effect on CBF, which occurred 2-5 min after stopping the NPY infusion: Coronary vascular resistance was estimated by the formula mean $\mathrm{AP} /$ mean $\mathrm{CBF}$, acknowledging that the value of coronary back pressure is uncertain but probably low in the open-chest $\operatorname{dog}(5)$.

Intramyocardial $\mathrm{pH}$ was measured in group $\mathrm{I}(n=7)$ to determine whether changes in CBF were severe enough to cause myocardial ischemia. Preliminary studies in this lab indicated the development of tissue acidosis was a reliable and sensitive index of myocardial ischemic injury, reflected by myocardial concentrations of ATP, creatine phosphate, and lactate. Intramyocardial $\mathrm{pH}$ was measured continuously during the basal state, after intracoronary infusion of saline (control), and after intracoronary infusion of NPY (42 nmol dissolved in $0.9 \%$ saline over $5.2 \mathrm{~min}$ ) into the circumflex artery in this group. Dead space of the catheter was $2.5 \mathrm{ml}$ so that the NPY began reaching the coronary circulation $40 \mathrm{~s}$ after the beginning of infusion. This dose of NPY was determined from preliminary studies identifying the maximum intracoronary dose that did not change heart rate or AP at the time of maximum effect on CBF, 5-10 min after stopping the infusion.

Intramyocardial $\mathrm{pH}$ was measured by a miniature fiberoptic $\mathrm{pH}$ probe system with four probes developed (5-7) and validated at the National Institutes of Health (NIH) (8) and elsewhere (9). Detailed description of the probe system is published elsewhere (5-8). The probes recorded $90 \%$ of their response to a step change in $\mathrm{pH}$ within 60 s. Two probes were implanted in the zone not infused with NPY and two in the infused zone. They were secured by rubber grommets at a depth of $3 \mathrm{~mm}$ below the epicardial surface for subepicardial $\mathrm{pH}$ and at $6 \mathrm{~mm}$ for subendocardial $\mathrm{pH}$ measurements. The dogs received 7,000 $\mathrm{U}$ of heparin via the femoral artery initially, then 5,000 U every $30 \mathrm{~min}$ to prevent clotting on the $\mathrm{pH}$ probe.

To test the presence of ischemia by an independent method, as well as to determine whether changes in intramyocardial $\mathrm{pH}$ were functionally significant, LVEF was measured by standard gated blood pool imaging techniques in two groups of dogs. In group II $(n=5) 42 \mathrm{nmol}$ of NPY were infused intracoronary into the left anterior descending artery over $5.2 \mathrm{~min}$. In group III $(n=7)$ a lower dose of NPY $(7 \mathrm{nmol})$ was infused intracoronary into the circumflex artery over $3.6 \mathrm{~min}$ to test if effects were dose related. After modified in vivo labeling with 20 $\mathrm{mCi}$ of technetium-99m, ECG-gated blood pool scintigraphy was performed by imaging the dog with a portable gamma scintillation camera (Elscint Inc., Boston, MA). The dog was imaged in a modified left anterior oblique projection which provided the best separation between right and left ventricles. The data were collected in list mode on a computer (Hewlett-Packard Co., Palo Alto, CA) over 6-10 min using programs developed at $\mathrm{NIH}$ as previously described (10) and adapted for our use in dogs (10 ms/frame) (11). LVEF was calculated as follows: (end-diastolic counts - end-systolic counts)/(end-diastolic counts background counts).

After the baseline gated blood pool scan, measurements were made of CBF, AP, left ventricular pressure, and heart rate. Saline was injected intracoronary at the same rate as a control in six dogs and caused no change in heart rate, CBF, AP, or LVEF. Repeat gated blood pool imaging and hemodynamic measurements were performed as soon as the infusion of NPY was completed to test reproducibility.

Large vs. small vessel resistance. To measure $R_{L}$ and $R_{S}$, we used the technique of Fam and McGregor (4) as previously reported in detail from this laboratory (12). First, we used dogs for this experiment only if their coronary anatomy was suitable for placing all instruments on the circumflex. A 23-gauge blunt needle with a tapered plastic tip was inserted retrograde into the smallest branch of the circumflex coronary artery that could be dissected and cannulated, $\sim 0.9 \mathrm{~mm}$ in diameter. The branch was ligated distally so that coronary pressure in the branch was measured through the proximally directed catheter connected to a pressure transducer. This transducer and a second identical pressure transducer were carefully balanced and calibrated against a mercury manometer in steps from 0 to $150 \mathrm{mmHg}$ to demonstrate linear responses over this range. These two pressure transducers were connected to a special electronic subtraction circuit, and the output was displayed on a physiological recorder. The subtraction circuit output was calibrated against mechanically calibrated signals in steps and amplified so that the full scale represented 0-20 $\mathrm{mmHg}$. In separate pilot studies femoral artery pressure was measured through a 23-gauge blunt needle and the usual 8 French aortic catheter. There was no difference in mean pressures when these two types of cannulas were inserted into two femoral arteries. The tubing was flushed with $1,000 \mathrm{U}$ of heparin and the dogs were heparinized with 7,000 $\mathrm{U}$ of heparin through the femoral artery initially and 5,000 $\mathrm{U}$ every half hour.

$R_{L}$ and $R_{S}$ were calculated in these dogs as follows $(4,12): R_{L}=(A P$ - DCP)/CBF and $\mathrm{R}_{S}=\mathrm{DCP} / \mathrm{CBF}$, where $\mathrm{DCP}=$ distal coronary pressure. The system was tested in each dog to confirm that it detected increases in $R_{L}$ induced by a brief partial inflation of the pneumatic occluder on the proximal coronary artery to decrease DCP and CBF.

NPY was obtained from Peninsula Laboratories, Inc., Belmont, $\mathrm{CA}$, as $0.2 \mathrm{mg}$ of dry powder per bottle, and its purity was confirmed by HPLC. NPY was dissolved in $20 \mathrm{ml}$ of $0.9 \%$ saline. The $\mathrm{pH}$ of saline alone was 7.27, but saline-NPY stock solution had pH of 7.30. NPY mixed in blood in vitro at $0.20 \mathrm{nmol} / \mathrm{ml}$, which was greater than the maximum calculated concentration in coronary blood in this experiment, caused no change in pH. NPY mixed in blood in vitro at 20.0 $\mathrm{nmol} / \mathrm{ml}, 100$ times the maximum calculated concentration in coronary blood in this experiment, increased $\mathrm{pH}$ by only $0.03 \mathrm{U}$.

Protocols (Table I). In group I $(n=7)$ NPY was infused into the circumflex coronary artery to a total dose of $42 \mathrm{nmol}$ in $20 \mathrm{ml}$ normal saline at $3.8 \mathrm{ml} / \mathrm{min}$ over $5.2 \mathrm{~min}$. This infusion rate was about $10 \%$ of the normal $\mathrm{CBF}$ rate. Intramyocardial $\mathrm{pH}$ was measured during basal states and after infusion of saline (control) and NPY. CBF, heart rate, and $\mathrm{AP}$ were also measured during the basal state and after completion of NPY infusion. Total time for experiments was $2-3 \mathrm{~h}$ after the initial thoracotomy incision.

In group II $(n=5)$ NPY was infused into the left anterior descending coronary artery to a total dose of $42 \mathrm{nmol}$ over $5.2 \mathrm{~min}$. CBF, heart rate, AP, and LVEF were measured during the basal state and after completion of saline (control) and NPY infusion.

In group III $(n=7)$ NPY $(10.5 \mathrm{nmol}$ in $20 \mathrm{ml}$ normal saline $)$ was infused into the circumflex coronary artery to a total of $13.4 \mathrm{ml}$ or 7 $\mathrm{nmol}$ at $3.8 \mathrm{ml} / \mathrm{min}$ over $3.6 \mathrm{~min}$. $\mathrm{CBF}$, heart rate, $\mathrm{AP}$, and $\mathrm{LVEF}$ were measured during the basal state and after completion of the NPY infusion, at the time of the maximum change in CBF. Measurements in groups II and III were recorded continuously during the 6-10-min of radionuclide image acquisition so that ejection fraction data are averaged over this period of time. Simultaneous measurements were recorded at the time of maximal changes in CBF. Group III dogs had pacing of the left ventricular apex at a constant rate, $10 \%$ above the basal rate, to be certain that NPY would not change heart rate.

In group IV $(n=6)$ NPY was administered into the circumflex coronary artery, $42 \mathrm{nmol}$ over $5.2 \mathrm{~min}$. CBF, AP, heart rate, and DCP were measured during the basal state and after NPY infusion, at the time of the maximum change in CBF.

Group V $(n=9)$ animals received NPY, $42 \mathrm{nmol}$ over $3.3 \mathrm{~min}(n$ $=5$ ), or $42 \mathrm{nmol}$ over $5.2 \mathrm{~min}(n=4)$ via the circumflex while recording lead II of the ECG. Criteria for development of an abnormality were $0.05 \mathrm{mV}$ ST segment shift or $50 \%$ change in T wave amplitude.

In group VI $(n=6)$ NPY was infused intravenously in a dose of 42 $\mathrm{nmol}$ in $5 \mathrm{ml}$ of saline over $1 \mathrm{~min}$ to evaluate whether coronary vasoconstriction could be produced by intravenous NPY, which would produce much lower coronary concentrations than would intracoronary administration.

Analysis of data. We tested the significance of changes from control to the maximum change after NPY by $t$ test for paired data (13). One way analysis of variance was used to test the significance of the doseresponse relationship for NPY. We presented the data as mean \pm SD. $P$ $<0.05$ was considered statistically significant. 


\begin{tabular}{|c|c|c|c|c|c|c|c|c|c|c|}
\hline \multirow[b]{2}{*}{ Group } & \multirow[b]{2}{*}{$n$} & \multirow[b]{2}{*}{ Route } & \multirow[b]{2}{*}{ Rate } & \multirow[b]{2}{*}{ Total } & \multicolumn{2}{|c|}{ Peak C-CAB } & \multirow{2}{*}{$\begin{array}{c}\text { CVR } \\
\text { (\% change) }\end{array}$} & \multirow{2}{*}{$\begin{array}{c}\text { LVEF } \\
\text { (\% change) }\end{array}$} & \multirow{2}{*}{$\begin{array}{c}\text { pHm-6 } \\
\text { (change) }\end{array}$} & \multirow[b]{2}{*}{ ECG ST-T } \\
\hline & & & & & $(\mathrm{nmol} / \mathrm{ml})$ & (ratio) & & & & \\
\hline & & & nmol/min & nmol & & & & & & \\
\hline I & 7 & IC & 7.0 & 42 & 0.167 & 7.6 & $+65 \%$ & $\mathrm{n} / \mathrm{a}$ & -0.08 & $\mathrm{n} / \mathrm{a}$ \\
\hline II & 5 & IC & 7.0 & 42 & 0.167 & 7.6 & $+62 \%$ & $-18 \%$ & $\mathrm{n} / \mathrm{a}$ & $\mathrm{n} / \mathrm{a}$ \\
\hline III & 7 & IC & 1.8 & 7 & 0.055 & 2.5 & $+46 \%$ & $-7 \%$ & $\mathrm{n} / \mathrm{a}$ & $\mathrm{n} / \mathrm{a}$ \\
\hline IV & 6 & IC & 7.0 & 42 & 0.171 & 7.7 & $+119 \%$ & $\mathrm{n} / \mathrm{a}$ & $\mathrm{n} / \mathrm{a}$ & $\mathrm{n} / \mathrm{a}$ \\
\hline V & 9 & IC & $12.5^{*}$ & 42 & 0.297 & 13.5 & $+74 \%$ & $\mathrm{n} / \mathrm{a}$ & $\mathrm{n} / \mathrm{a}$ & 8 of 9 \\
\hline VI & 6 & IV & 42.0 & 42 & 0.015 & 0.7 & $+59 \%$ & $\mathrm{n} / \mathrm{a}$ & $\mathrm{n} / \mathrm{a}$ & $\mathrm{n} / \mathrm{a}$ \\
\hline
\end{tabular}

n/a, Not available; IC, intracoronary route; IV, intravenous route; C-CAB, concentration in coronary arterial blood (NPY infusion rate/coronary arterial blood flow rate); $\mathrm{CVR}$, coronary vascular resistance ( $\mathrm{AP} / \mathrm{CBF}=\mathrm{mmHg} / \mathrm{ml}$ per min); $\mathrm{pHm}-6$, intramyocardial $\mathrm{pH} 6 \mathrm{~mm}$ below epicardial surface; ECG ST-T, changes in ST-T waves of ECG to suggest ischemia induced by NPY in this number of dogs; ratio, C-CAB/CCAW, where C-CAW = concentration of NPY in human coronary arterial wall (C-CAW) postmortem measured by RIA $=0.020 \mathrm{nmol} / \mathrm{g}(2)$. * Maximum rate in 5 of 9 dogs in group V. Four dogs had maximum rate of $42 \mathrm{nmol}$ over $5.2 \mathrm{~min}$.

\section{Results}

In group I $(n=7)$, given $42 \mathrm{nmol}$ of intracoronary NPY, there was no change in heart rate $(113 \pm 35$ to $106 \pm 32$ beats $/ \mathrm{min})$ or mean AP (104 \pm 14 to $105 \pm 11$ ), while CBF decreased $39 \%$ from a control of $41 \pm 13$ to $25 \pm 9 \mathrm{ml} / \mathrm{min}(P<0.002$; Fig. 1$)$. Coronary vascular resistance increased $65 \%$ from $2.93 \pm 1.24$ $\mathrm{mmHg} / \mathrm{ml}$ per min $(P<0.002)$. To determine whether this decrease in CBF was severe enough to cause ischemia, intramyocardial $\mathrm{pH}$ was measured. Fig. 2 shows a typical $\mathrm{pH}$ experiment in which NPY caused a decrease in CBF which preceded a drop in $\mathrm{pH}$ of the infused zone. The $\mathrm{pH}$ dropped from $7.45 \pm 0.06$ to $7.37 \pm 0.06$ after NPY in the subendocardium of the zone infused with NPY $\left(\mathrm{IZ}_{6}\right)(P<0.0002$; Fig. 3$)$. In the subepicardium of the zone infused with NPY, the $\mathrm{pH}$ dropped from $7.45 \pm 0.06$ to $7.40 \pm 0.05 \mathrm{pH}$ units $(P<0.04$; Fig. 3 ), a smaller $\mathrm{pH}$ drop than occurred in the subendocardium $(P$
$<0.05)$. In the subendocardium of the zone not infused with NPY, the $\mathrm{pH}$ did not change from control $(7.44 \pm 0.06$ to $7.44 \pm 0.06$; Fig. 3). The $\mathrm{pH}$ in the subepicardium not infused with NPY was the same as the subendocardium. The development of acidosis in the infused zones indicates that NPY causes a sufficiently severe reduction in CBF to produce myocardial ischemia.

To document the occurrence of ischemia by an independent method and to determine the functional significance of the pH change, LVEF was measured in two groups. In group II gated blood pool imaging was performed in five dogs that received the same dose of NPY as group I (42 nmol over 5.2 $\mathrm{min}$ ) in the left anterior descending coronary artery. There was no significant change in heart rate $(65 \pm 10$ to $63 \pm 12$ beats/ min) even though the dogs were not paced. AP did not change significantly ( $117 \pm 13$ to $121 \pm 14 \mathrm{mmHg})$, but CBF decreased $36 \%$ from $43 \pm 11$ to $28 \pm 6 \mathrm{ml} / \mathrm{min}(P<0.005$; Fig. 1$)$. LVEF
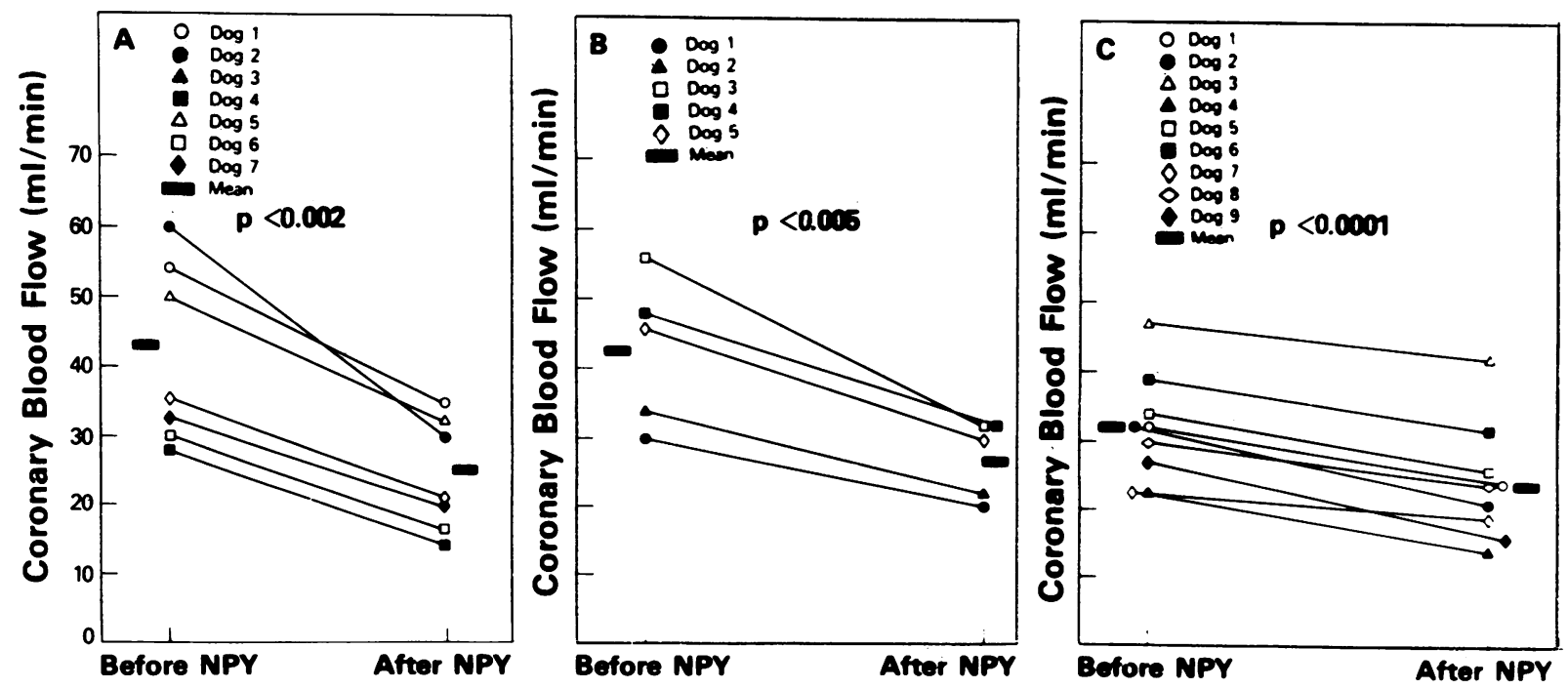

Figure 1. These graphs show that NPY decreased CBF in groups I, II, and III. $p H$, dogs in which intramyocardial pH was recorded; $R N C$, dogs in which radionuclide angiocardiograms were recorded. (A) Group I (42 nM NPY, pH); (B) group II (42 nM NPY, RNC); (C) group III (7 nM NPY, RNC). 


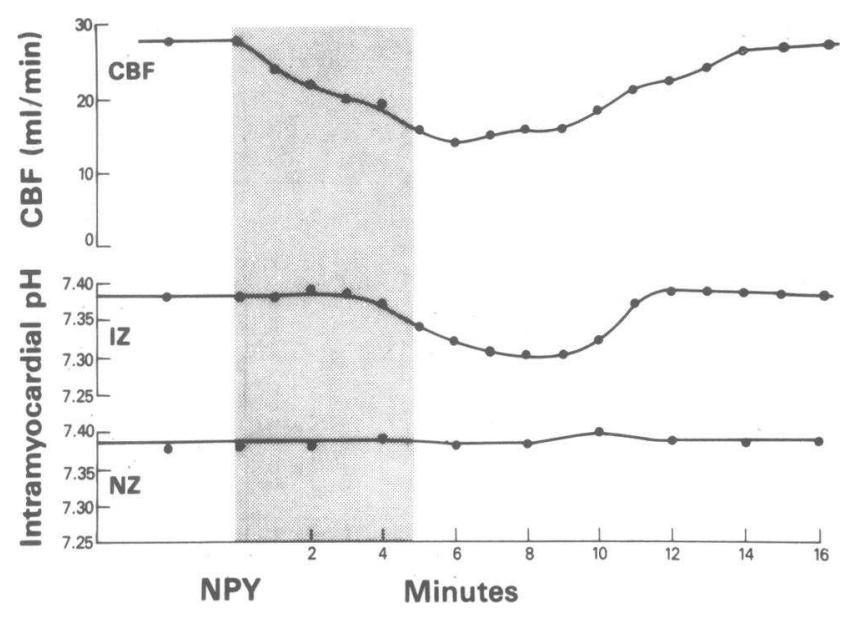

Figure 2. This graph shows results of one $\mathrm{pH}$ experiment. The development of acidosis follows and coincides closely with the drop in CBF in the subendocardial zone infused with NPY (IZ), while the $\mathrm{pH}$ of the noninfused zone $(N Z)$ does not change. The shaded area shows the duration of the NPY infusion.

decreased by $0.10 \mathrm{U}$ or $18 \%$ from $0.52 \pm 0.08$ to $0.42 \pm 0.12(P$ $<0.01$; Fig. 4). In group III $(n=7)$ gated blood pool imaging was performed before and after a lower dose of NPY $(7 \mathrm{nmol})$; there was no change in heart rate $(102 \pm 16$ to $103 \pm 16$ beats/ $\mathrm{min})$ or $\mathrm{AP}(104 \pm 15$ to $107 \pm 16 \mathrm{mmHg})$, while $\mathrm{CBF}$ decreased $22 \%$ from $32 \pm 8$ to $25 \pm 10 \mathrm{ml} / \mathrm{min}(P<0.0001$; Fig. 1$)$. Coronary vascular resistance increased $46 \%$ from $3.38 \pm 0.85$ to $4.93 \pm 1.99 \mathrm{mmHg} / \mathrm{ml}$ per $\min (P<0.025)$. In this group, receiving a lower dose of NPY, the decrease in CBF and the increase in coronary vascular resistance were less than in the groups receiving a higher dose $(P<0.05)$. LVEF decreased by $7 \%$ from $0.36 \pm 0.07$ to $0.34 \pm 0.001 \mathrm{U}(P<0.06$; Fig. 4).

Groups II and III, therefore, demonstrate a dose-related decrease in LVEF associated with NPY-induced vasoconstriction (Fig. $4 \mathrm{C}$ ). The dose-related decrease in LVEF is closely related to the dose-related decrease in CBF produced by NPY (plotted in deciles of percent decrease in CBF; Fig. 5).
In group IV $(n=6)$, given $42 \mathrm{nmol}$ of intracoronary NPY, there was no significant change in heart rate $(92 \pm 40$ to $74 \pm 21$ beats/min) or AP $(102 \pm 13$ to $109 \pm 13 \mathrm{mmHg})$, while $\mathrm{CBF}$ decreased $45 \%$ from $38 \pm 11$ to $21 \pm 9 \mathrm{ml} / \mathrm{min}(P<0.005)$. Total coronary vascular resistance increased by $119 \%$ from $2.83 \pm 0.88 \mathrm{mmHg} / \mathrm{ml}$ per $\min (P<0.01)$. To determine whether the predominant site of this vasoconstriction was in large or small vascular arteries, $R_{L}$ and $R_{S}$ were calculated from flow and pressure gradients (Fig. 6). $R_{L}$ increased $86 \%$ from $0.22 \pm 0.07 \mathrm{mmHg} / \mathrm{ml}$ per min, but this change was not significant (Fig. 7). $R_{S}$ increased $122 \%$ from $2.61 \pm 0.82$ $\mathrm{mmHg} / \mathrm{ml}$ per $\min (P<0.01$; Fig. 7$)$. As expected, $\mathbf{R}_{\mathbf{S}}$ accounted for $90 \%$ of the total coronary vascular resistance before NPY, and the results show that $R_{S}$ accounted for $92 \%$ of the total coronary vascular resistance after NPY. Of the increase in total coronary vascular resistance, $94 \%$ was due to increases in $R_{S}$ and only $6 \%$ to increases in $R_{L}$. Small coronary arteries exerted predominant control of coronary circulation during both control conditions and vasoconstriction due to NPY. Baseline measurements did not change after intracoronary saline infusion.

In group V $(n=9)$ NPY caused a similar increase in coronary vascular resistance (74\%) as in the other groups, and ST-T wave changes were noted in eight of nine dogs.

In group VI $(n=6) 42 \mathrm{nmol}$ of NPY were infused intravenously to determine whether a 30- to 50-fold lower concentration of NPY administered by a more convenient route could cause coronary vasoconstriction. CBF decreased $33 \%$ from $33 \pm 7$ to $22 \pm 7 \mathrm{ml} / \mathrm{min}(P<0.001)$. Coronary vascular resistance increased $59 \%$ from $2.78 \pm 1.45 \mathrm{mmHg} / \mathrm{ml}$ per min $(P$ $<0.01)$. Heart rate $(119 \pm 25$ to $108 \pm 31$ beats $/ \mathrm{min})$ and AP ( $86 \pm 22$ to $91 \pm 20 \mathrm{mmHg}$ ) did not change.

In control studies $\mathrm{CBF}$ and intramyocardial $\mathrm{pH}(n=6)$ did not change after intracoronary saline infusion at the same volume and rate as NPY. The average $\mathrm{pH}$ change in the subendocardium of the zone infused with saline was $0.004 \pm 0.008$ $\mathrm{pH}$ units. Changes of +0.020 or -0.012 are within the $95 \%$ confidence limits. The average $\mathrm{pH}$ change in the subepicardium of the zone infused with saline was $0.003 \pm 0.005 \mathrm{pH}$ units. Changes of +0.007 or -0.013 are within the $95 \%$ confi-
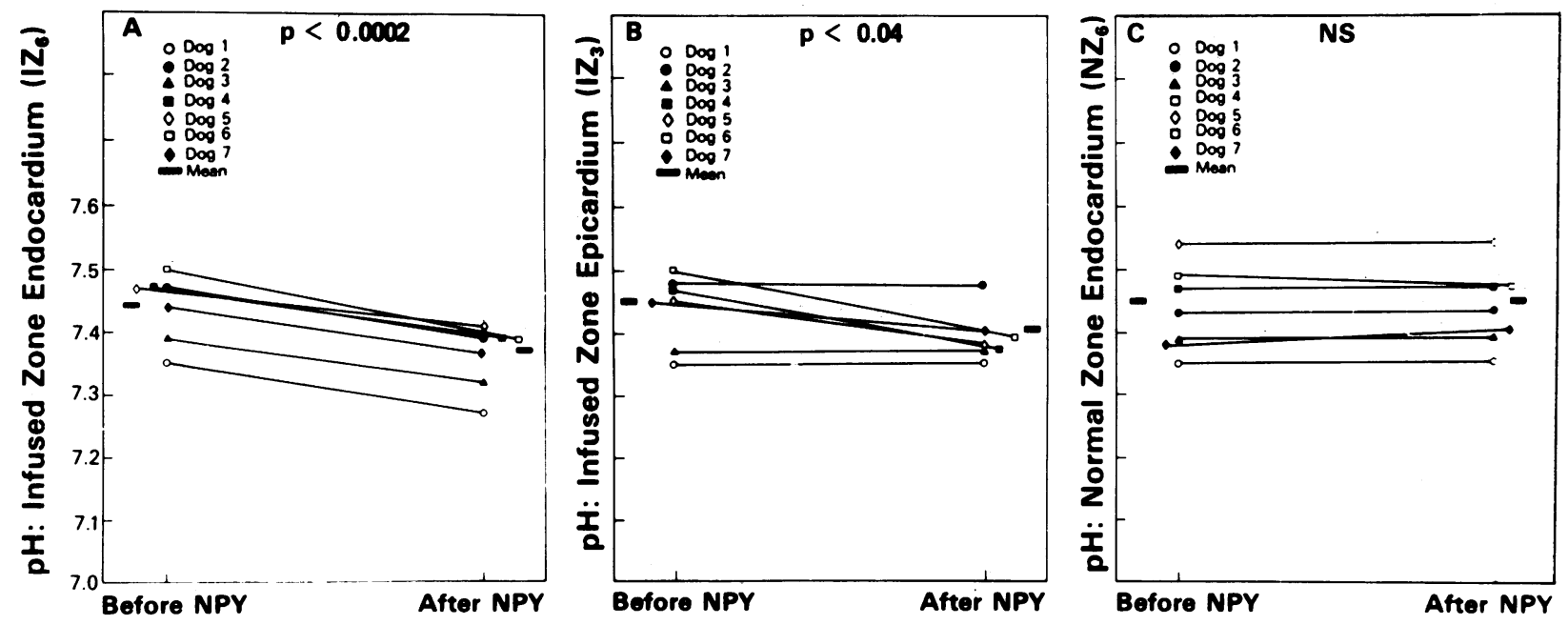

Figure 3. These graphs summarize the effect of NPY on intramyocardial pH in group I dogs. NPY decreased pH in the subendocardium and subepicardium of the infused zone but did not change $\mathrm{pH}$ in the noninfused zone. 

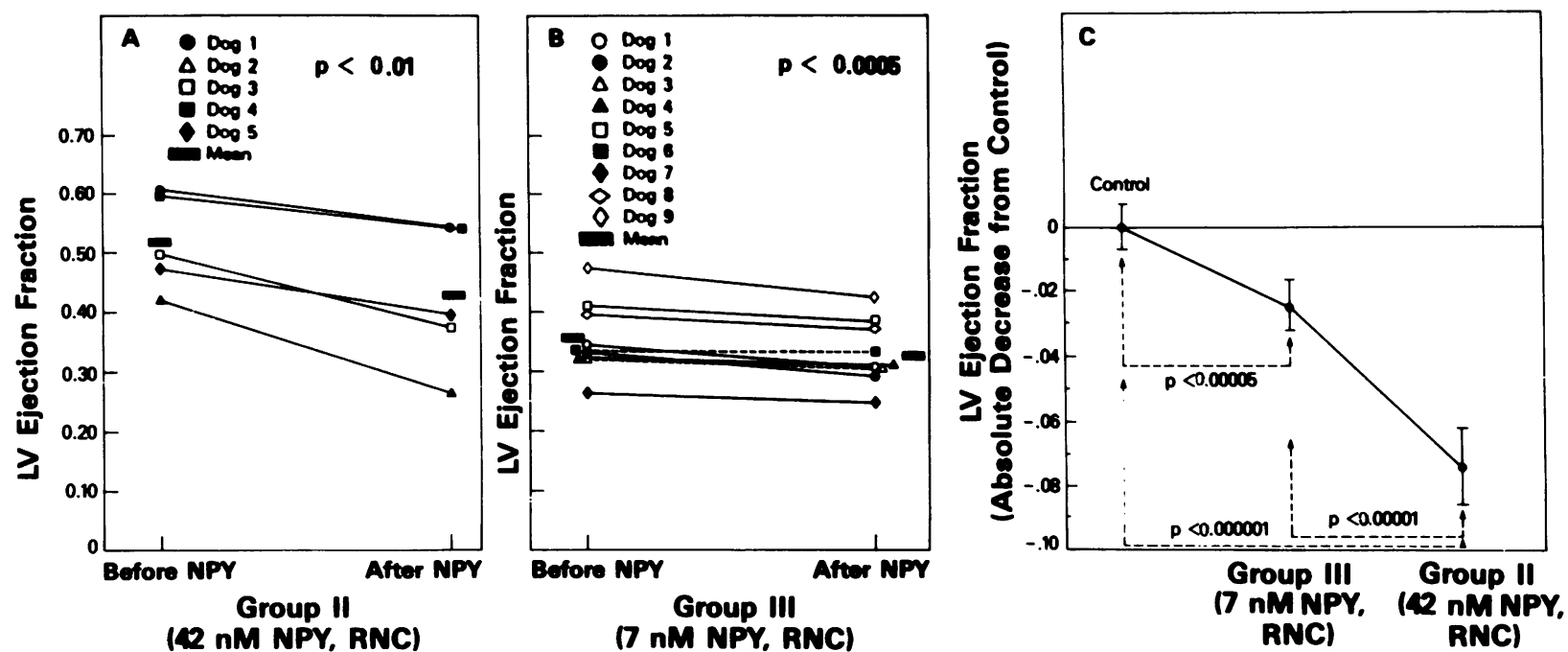

Figure 4. These graphs show a decrease in left ventricular $(L V)$ ejection fraction associated with NPY-induced vasoconstriction in $A$ and $B$. $C$ shows that this decrease in LVEF is dose related $(P<0.001$ by analysis of variance to compare the slope of the line with zero).

dence limits; therefore, a decrease of $>0.014$ would be signifcant at $P<0.05$. Further, the magnitude of $\mathrm{pH}$ drop (e.g., -0.08 in $\mathrm{IZ}_{6}$ ) observed in these experiments with a transient $39 \%$ decrease in $\mathrm{CBF}$ is consistent with our observations of $\mathrm{pH}$ drop during sustained 20 -min partial coronary flow reductions: -0.07 for a $25 \%$ reduction and -0.32 for a $50 \%$ reduction. LVEF also did not change after intracoronary saline infusion (absolute difference $=0.01 \pm 0.01$ ). These ejection fractions were measured in the same dog a few minutes apart without evidence of change in $\mathrm{CBF}$, heart rate, or $\mathrm{AP}$.

\section{Discussion}

$\mathrm{NPY}$ is a 36 amino acid residue with tyrosine as its $\mathrm{NH}_{2}$-terminal amino acid, first isolated from porcine brain in 1982 (14). Dense concentrations have recently been found in human large coronary arteries $(0.020 \pm 0.006 \mathrm{nmol} / \mathrm{g})$ by incubation with NPY antiserum (2). Abdominal sympathectomy caused disappearance of some NPY fibers, notably those around the

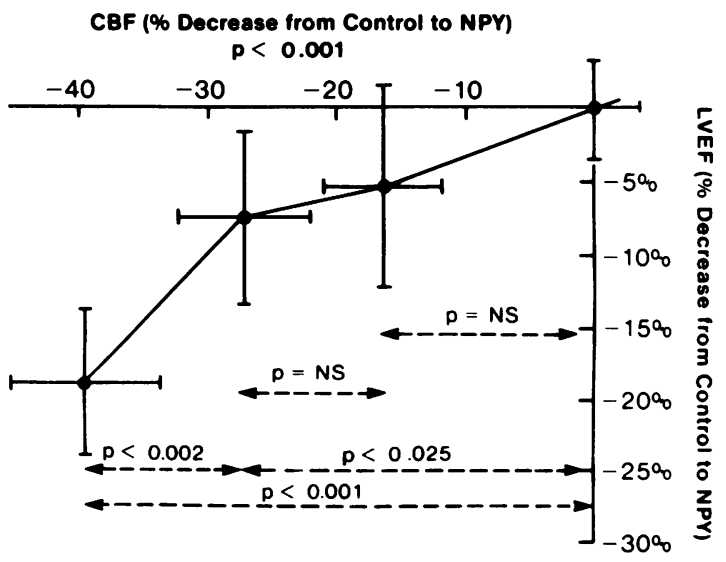

Figure 5. This graph shows that the dose-related changes in LVEF are explained by a dose-related decrease in coronary blood flow $(P$ $<0.001$ by one-way analysis of variance, as indicated on horizontal axis label). blood vessels (15). NPY immunoreactivity was observed in a population of sympathetic ganglion cells in the rat, guinea pig, cat, and human (16).

Local intraarterial infusion of NPY at $100 \mathrm{nmol} / \mathrm{min}$ yielded a calculated peak arterial concentration of $143 \mathrm{nmol} /$ $\mathrm{ml}=(100 \mathrm{nmol} / \mathrm{ml}) /(0.7 \mathrm{ml} / \mathrm{min})$. This dose induced vasoconstriction in the cat submandibular gland that was resistant to alpha adrenoreceptor blockade (3). NPY also increased aortic blood pressure upon intravenous administration $(0.1$ $\mathrm{nmol} / \mathrm{kg}$ ) in the cat to indicate systemic vasoconstrictor effects of NPY in sufficiently large doses (3).

The effect of NPY on the coronary circulation is not known. The mechanism of physiological and pathological coronary vasoconstriction is also not understood. Chemical mediators such as prostaglandins have been proposed, but cyclooxygenase inhibitors did not prevent pathological vasoconstriction in man $(17,18)$. Neural involvement has been suggested

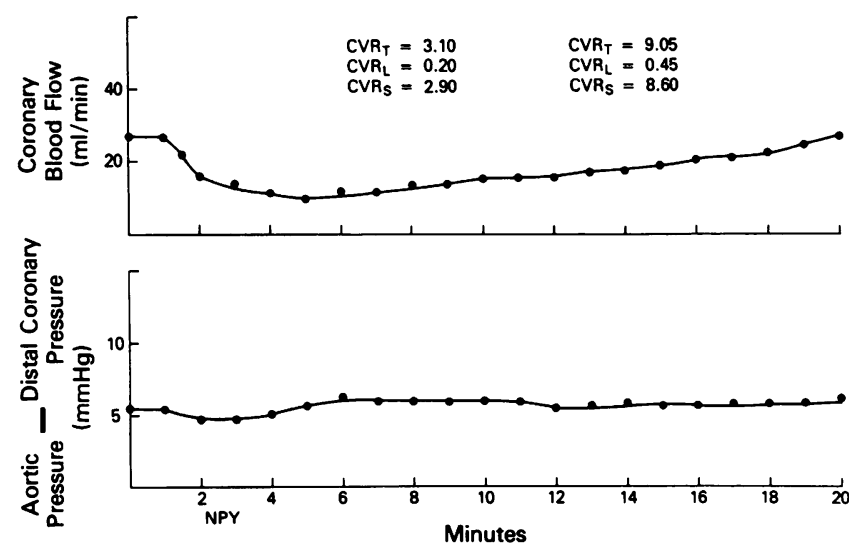

Figure 6. Effects of NPY on CBF and the gradient between AP and DCP in one experiment. Decreased flow in this experiment with no real change in the pressure gradient indicates no change in large vessel resistance. NPY was infused during the time period just before 1 to just before $6 \mathrm{~min}$. $C V R$, coronary vascular resistance, either $(L)$ of large vessels, $(S)$ of small vessels, or $(T)$ total $(L+R)$, measured in $\mathrm{mmHg} / \mathrm{ml}$ per min. 


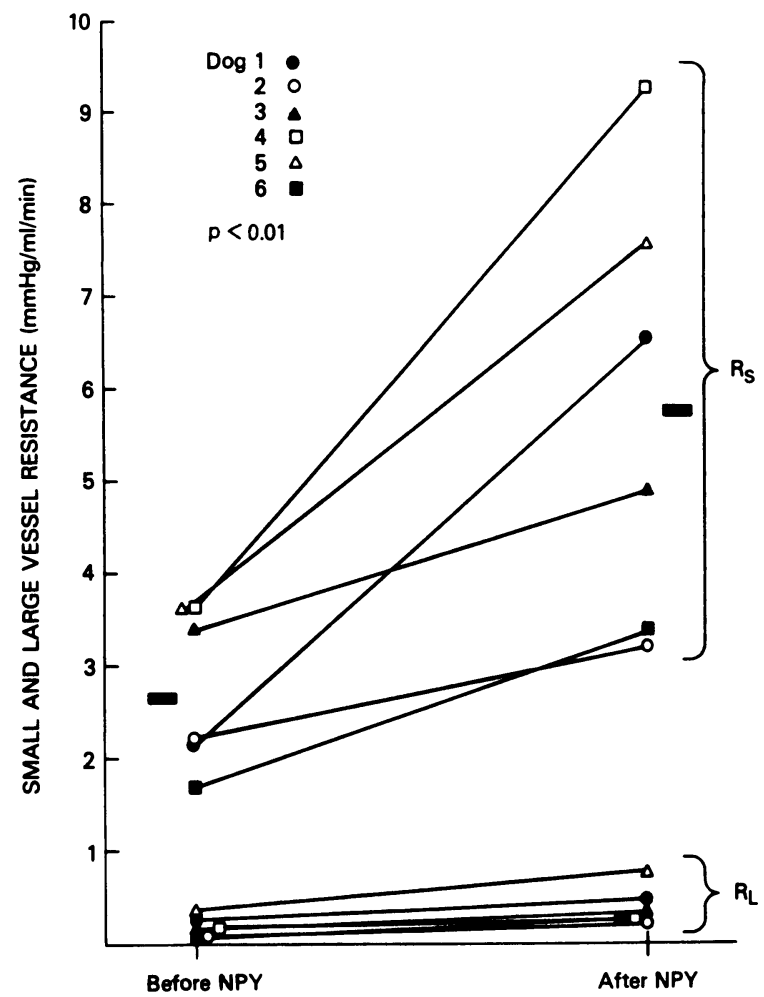

Figure 7. Effects of NPY on $R_{L}$ and $R_{S}$. The increase in $R_{S}$ was significant $(P<0.01)$, but the increase in $R_{L}$ was not. Note also that $R_{S}$ contributes much more than $R_{L}$ to total resistance $\left(R_{S}+R_{L}\right)$ before and after NPY.

by the clinical association of coronary vasoconstriction with emotional stress (19) and cold pressor tests (20), but alpha adrenergic receptor blockers did not prevent pathological vasoconstriction in humans (21). It thus seems worthwhile to consider other potential neurotransmitters, such as neuropeptides (22).

As a first step in this evaluation, these results showed that NPY caused a dose-related decrease in CBF without changing heart rate or AP. This vasoconstriction was severe enough to produce regional myocardial ischemia, as documented by a decrease in intramyocardial $\mathrm{pH}$ that was greater in the subendocardium than in the subepicardium of the infused zone. Finally, NPY-induced vasoconstriction caused ST-T wave changes on the ECG and a dose-related decrease in LVEF to corroborate the development of ischemia by independent methods and demonstrate the functional significance of the decreases in $\mathrm{CBF}$ and intramyocardial $\mathrm{pH}$.

Normally, regulatory mechanisms control CBF to meet myocardial metabolic demands (23). CBF regulation may be mediated by vasodilator metabolites such as adenosine (24), produced from ischemic cardiac cells and released into extracellular fluid around small coronary arterial branches (23). Thus, ischemia caused by a coronary vasoconstrictor could be explained most easily by constriction of large epicardial coronary arteries which are remote from the metabolic milieu where vasodilator metabolites are produced. In fact, the most widely recognized form of coronary vasoconstriction in man has been due to spasm of large coronary arteries (19); but other clinical studies suggest that constriction of small rather than large coronary arteries can cause myocardial ischemic syndromes in many patients with variable threshold angina (25).
Using the pressure-gradient techniques of Fam and McGregor (4), we found increases in $R_{L}$ and $R_{S}$ with NPY, but only the increase in $R_{S}$ was significant. Further, the increase in $\mathbf{R}_{\mathrm{S}}$ accounted for $90 \%$ of the total coronary vascular resistance before and $92 \%$ after NPY, while $R_{L}$ accounted for only $10 \%$ of total coronary vascular resistance before and $8 \%$ after NPY. These data indicate that small coronary arteries exert predominant control of the coronary circulation during basal conditions, as expected, but also during vasoconstriction due to NPY. The change in total coronary vascular resistance with NPY was accounted for primarily $(94 \%)$ by the increase in $\mathbf{R}_{\mathbf{S}}$. Thus, these results suggest that NPY may compete directly at the level of small coronary arteries to overcome the endogenous regulation of CBF. It is known that NPY is present in large coronary arteries (2), but its relative concentration in small arteries is not known.

Critique of methods. In this study we used open-chest dogs anesthetized with alpha chloralose to minimize cardiovascular effects of anesthesia $(26,27)$. We believe that the observed drop in intramyocardial $\mathrm{pH}$ in the subendocardium and subepicardium of the infused zone represents ischemia. Measurements of intramyocardial $\mathrm{pH}$ by the fiberoptic $\mathrm{pH}$ probes have been shown to correlate closely with other indexes of ischemic injury during mechanical occlusion, such as $\mathrm{CBF}(r=0.80 ; 8)$, the depletion of ATP $(r=0.79)$, creatine phosphate $(r=0.76)$, and the accumulation of lactate in tissue $(r=-0.88) 15 \mathrm{~min}$ after CBF reduction in our laboratory. Further evidence of ischemia is provided in this study by the fact that the $\mathrm{pH}$ drop was greater in the subendocardium than in the subepicardium (8), as shown during coronary occlusion (8).

The observed drop in LVEF from $0.52 \pm 0.08$ to $0.42 \pm 0.12$ in group II provides strong evidence of left ventricular dysfunction. Group III dogs show a smaller decrease in LVEF. The results of group III can be incorporated into a dose-response curve that shows that the decrease in LVEF is related to the dose, as seen in Fig. 4. This curve of ejection fraction vs. dose can be explained by a dose-related decrease in CBF as seen in Fig. 5.

We believe that this decrease in LVEF can be interpreted as evidence of ischemia. Other potential causes of left ventricular dysfunction could not account for the change. First, AP did not change, so the decreased ejection fraction could not be attributed to increased afterload (28) or to baroreceptor reflexinhibition of contractile function (29). Second, a direct negative inotropic effect of NPY would not be expected to cause the magnitude of decrease in CBF that was observed in the present study (30), and a negative inotropic effect would not cause the decrease in intramyocardial $\mathrm{pH}$ seen in group I or ST-T wave changes as seen in group VI. Further, if data from another study from this lab (31) are plotted on Fig. 5, that point fits the line constructed from data in the present study; i.e., mechanical coronary occlusion decreased flow by $86 \%$ and ejection fraction by $35 \%$. These data support the interpretation that the decrease in ejection fraction with NPY resulted from the decrease in flow. Thus, four separate lines of evidence, including a dose-related decrease in coronary flow, a decrease in intramyocardial pH, ECG ST-T wave changes, and a decrease in LVEF combine to provide very strong evidence that NPY causes coronary vasoconstriction severe enough to produce myocardial ischemia. The finding that the dose-related reduction in $\mathrm{CBF}$ at constant heart rate and $\mathrm{AP}$ would impair left ventricular function is consistent with the finding of sev- 
eral studies that a $10-20 \%$ decrease in CBF impaired cardiac contraction (32-34).

Next, to compare effects of NPY on $R_{L}$ and $R_{S}$, we selected the only technique that makes both measurements simultaneously and in comparable units. $R_{L}$ and $R_{S}$ were determined from pressure differences between AP and DCP $(4,12)$. The limiting step in estimating the site of vasoconstriction by this method is the size of the coronary branch that can be cannulated for pressure measurements $(\sim 0.9-\mathrm{mm}$-diam $)$. This catheter in the coronary artery was directed retrograde $4-6 \mathrm{~cm}$ from the origin of the left coronary artery to assure adequate mixing and exposure of the large, proximal coronary arteries to the infused peptide. Inflation of the pneumatic occluder on the left circumflex coronary artery caused a large drop in pressure between the aorta and the distal coronary catheter to prove that the system could detect spasm of large coronary arteries (12) such as is observed on angiography (19). Pilot studies also showed that intracoronary nitroglycerin decreased primarily $R_{L}$ to prove that infused drugs had their expected effects. This pressure gradient method has distinguished the primary site of action of several compounds $(4,12,35-37)$ and excluded the possibility that NPY acted primarily on the large epicardial coronary arteries to cause vasoconstriction and spasm of the type observed by coronary arteriography. This does not mean that intracoronary NPY has no effect on $R_{L}$, but rather that the increase in total coronary vascular resistance was explained primarily $(94 \%)$ by the increase in $R_{S}$. Further, no study has compared the relative concentration of NPY in large vs. small coronary arteries (2).

Several aspects of this study indicate that intracoronary infusion of NPY could expose the proximal coronary artery to enough NPY to test its responses: $(a)$ dogs with suitable coronary anatomy were selected to assure a 4-6-cm distance between the origin of the left coronary artery and the catheter used to measure distal pressure; $(b)$ the NPY infusion catheter was inserted retrograde to provide a "mixing chamber" 3-5 $\mathrm{cm}$ long; and $(c)$ the estimated velocity of the infusion was about 10 times greater than the velocity of coronary flow to promote mixing. In pilot studies intracoronary nitroglycerin primarily decreased $R_{L}$, as expected (35-37), while methoxamine increased $R_{L}$ using this same system (12).

It is difficult to assess the potential physiological or pathological relevance of the doses of NPY infused exogenously in the present study. Since little is known about NPY turnover, concentrations, or functions, it seems important to explore a wide range of concentrations, e.g., a 20 -fold range of estimated arterial concentrations in the present study (Table I). The concentrations infused directly into the coronary artery were estimated to be 2.5-13.5 times the concentrations reported in the coronary arterial wall by RIA (2). A much lower arterial concentration was estimated after intravenous infusion: 0.015 $\mathrm{nmol} / \mathrm{ml}$, or $30 \%$ less than the arterial wall concentration. The arterial wall concentration might be expected to be normally higher than arterial blood since NPY is derived from nerve endings that are present in the arterial wall (1-3). Thus, all of these calculated ratios probably overestimate the degree to which these NPY doses exceed physiological concentrations. The fact that even low concentrations of NPY produced coronary vasoconstriction suggests that the doses used are relevant. The peak arterial concentrations of NPY used by Lundberg and Tatemoto (3) can be calculated to be $143 \mathrm{nmol} / \mathrm{ml}$ or 480 to 2,600-fold higher than the dose range used in the present study (Table I). It seems clear that the NPY doses in the present study are not grossly excessive because they did not even raise aortic blood pressure. Further, exogenously infused agents that probably act at nerve endings would need to be infused in high arterial concentrations to pass through the arterial wall to the site of action in the nerve endings. Exogenous infusions would be expected to require high concentrations to mimic the effects of endogenously released NPY. The ultimate reason for interest in NPY is that it may play a role in the pathophysiology of coronary artery disease. If NPY plays a role in disease states, it is likely that either the local NPY concentration is too high or the artery would be sensitized to the effect of NPY. Thus, it would seem remiss to obtain physiological data only at low concentrations of NPY. Finally, no data obtained in healthy animals will define the potential relevance of NPY to human coronary artery disease. That goal is several steps away from the objectives of these studies of the actions of NPY. The present results suggest, however, that NPY deserves further evaluation as a possible mediator of human coronary vasoconstriction.

\section{Acknowledgments}

The authors are grateful for expert preparation of the manuscript by Mrs. Gail Gipson and Imogene Surrey.

Some of the experiments were supported by the Carlyle Fraser Heart Center of Emory University and research grant number RO1HL34558 from the National Heart, Lung, and Blood Institute, NIH, Bethesda, MD.

\section{References}

1. Tatemoto, K., M. Carlquist, and V. Mutt. 1982. Neuropeptide Y: a novel brain peptide with structural similarities to peptide $Y Y$ and pancreatic peptide. Nature (Lond.). 296:659-660.

2. Gu, J., T. E. Adrian, K. Tatemoto, J. M. Polak, J. M. Allen, and S. R. Bloom. 1983. Neuropeptide tyrosine (NPY): a major cardiac neuropeptide. Lancet. i:1008-1010.

3. Lundberg, J. M., and K. Tatemoto. 1982. Pancreatic polypeptide family (APP, BPP, NPY and PYY) in relation to sympathetic vasoconstriction resistant to alpha blockade. Acta Physiol. Scand. 116:393-402.

4. Fam, W. M., and M. McGregor. 1969. Pressure-flow relationships in the coronary circulation. Circ. Res. 25:293-301.

5. Goldstein, S. R., J. I. Peterson, and R. V. Fitzgerald. 1989. A miniature fiberoptic pH sensor for physiologic use. J. Biomech. Eng. 102:141-146.

6. Peterson, J. I., S. R. Goldstein, R. V. Fitzgerald, and D. K. Buckhold. 1980. Fiberoptic pH probe for physiologic use. Anal. Chem. 52:864-969.

7. Markle, D. R., D. A. McGuire, S. R. Goldstein, R. E. Patterson, and R. M. Watson. 1981. A pH measurement system for use in tissue and blood employing miniature fiber optic probes. In Advances in Bioengineering. D. Viano, editor. American Society of Mechanical Engineering, New York. 123-126.

8. Watson, R. M., D. R. Markle, Y. M. Ro, D. A. McGuire, J. I. Peterson, S. R. Goldstein, and R. E. Patterson. 1984. Transmural pH gradient in canine myocardial ischemia. Am. J. Physiol. 246:H232238.

9. Tait, G. A., R. B. Young, G. J. Wilson, D. J. Steward, and D. C. MacGregor. 1982. Myocardial $\mathrm{pH}$ during regional ischemia: evaluation of a fiberoptic photometric probe. Am. J. Physiol.: Heart, Circ. Physiol. 12:H1027-H1031.

10. Green, M. V., W. Brody, M. A. Douglas, J. S. Borer, H. G. Ostrow, B. R. Line, S. L. Bacharach, and G. S. Johnson. 1978. A count 
based method for determination of ejection fraction from radionuclide angiograms. J. Nucl. Med. 19:880-883.

11. Green, M. V., B. A. Jones-Collins, S. L. Bacharach, S. L. Findley, R. E. Patterson, and S. M. Larson. 1984. Prolongation of regional time to left ventricular end-systole during acute myocardial ischemia: a scintigraphic study in the dog. J. Am. Coll. Cardiol. 4:72-79.

12. Maturi, M. F., R. Greene, B. Donohue, L. M. A. Dorsey, M. V. Green, S. L. Bacharach, D. Vitale, and R. E. Patterson. 1986. Functional consequences and intracoronary localization of alpha-adrenergic stimulation of the canine coronary circulation. J. Am. Coll. Cardiol. 8:885-893.

13. Snedecor, G. W., and W. G. Cochran. 1967. Statistical Methods. 6th ed. Iowa State University Press, Ames, IA. 1-298.

14. Tatemoto, K. 1982. Neuropeptide Y: complete amino acid sequence of the brain peptide. Proc. Natl. Acad. Sci. USA. 79:54855489.

15. Sundler, F., E. Moghimzadeh, R. Hakanson, M. Ekelund, and P. Emson. 1983. Nerve fibers in the gut and pancreas of the rat displacing neuropeptide-Y immunoreactivity. Cell. Tissue Res. 230:487-493.

16. Lundberg, J., L. Terenius, T. Hokfelt, C. R. Martling, K. Tatemoto, V. Mutt, J. Polak, S. Bloom, and M. Goldstein. 1982. Neuropeptide Y (NPY)-like immunoreactivity in peripheral noradrenergic neurons and effects of NPY on sympathetic function. Acta Physiol. Scand. 116:477-480.

17. Robertson, R. M., D. Robertson, L. J. Roberts, R. L. Maas, G. A. Fitzgerald, G. C. Friesinger, and J. A. Oates. 1981. Thromboxane $A_{2}$ in vasotonic angina pectoris: evidence from direct measurements and inhibitory trials. N. Engl. J. Med. 304:998-1003.

18. Chierchia, S., R. DeCaterna, F. Crea, C. Patrono, and A. Maseri. 1982. Failure of thromboxane $A_{2}$ blockade to prevent attacks of vasospastic angina. Circulation. 66:702-705.

19. Maseri, A., and S. Chierchia. 1982. Coronary artery spasm: demonstration, definition, diagnosis, and consequences. Prog. Cardiovasc. Dis. 25:169-192.

20. Mudge, G. H., Jr., W. Grossman, R. M. Mills, Jr., M. Lesch, and E. Braunwald. 1976. Reflex increase in coronary vascular resistance in patients with ischemic heart disease. N. Engl. J. Med. 295:1333-1337.

21. Chierchia, S., G. Davies, G. Berkenboom, F. Crea, P. Crean, and A. Maseri. 1984. Alpha-adrenergic receptors and coronary spasm: an elusive link. Circulation. 69:8-14.

22. Krieger, D. T., and J. B. Martin. 1981. Brain peptides. N. Engl. J. Med. 304:876-885.
23. Berne, R. M., and R. Rubio. 1979. Coronary circulation. In Handbook of Physiology, Vol. 1. R. M. Berne, N. Sperelakis, and S. R. Geiger, editors. Waverly Press, Baltimore. 873-938.

24. Berne, R. M. 1980. Brief reviews: the role of adenosine in the regulation of coronary blood flow. Circ. Res. 47:807-813.

25. Cannon, R. O., R. M. Watson, D. R. Rosing, and S. E. Epstein. 1983. Angina caused by reduced vasodilator reserve of the small coronary arteries. J. Am. Coll. Cardiol. 1:1359-1373.

26. Afors, K. E., G. Arturson, and P. Mulmberg. 1971. Effect of prolonged chloralose anesthesia on acid-base balance and cardiovascular functions in dogs. Acta Physiol. Scand. 81:47-53.

27. Vatner, S. F., and E. Braunwald. 1975. Cardiovascular control mechanisms in the conscious state. N. Engl. J. Med. 293:970-976.

28. Frank, O. 1959. On the dynamics of cardiac muscle. Am. Heart J. 58:282-287.

29. Heyndrickx, G. R., D. H. Boettcher, and S. Vatner. 1976. Effects of angiotension vasopressin and methoxamine on cardiac function and blood flow distribution in conscious dogs. Am. J. Physiol. 231:1579-1587.

30. Parratt, J. R. 1980. Effects of adrenergic activators and inhibitors on the coronary circulation. Handb. Exp. Pharmacol. 54:735-822.

31. Urquhart, J., R. E. Patterson, S. L. Bacharach, M. V. Green, E. H. Speir, R. Aamodt, and S. E. Epstein. 1984. Comparative effects of verapamil, diltiazem and nifedipine on hemodynamics and left ventricular function during acute myocardial ischemia in dogs. $\mathrm{Circu}$ lation. 69:382-390.

32. Vatner, S. F. 1980. Correlation between acute reductions in myocardial blood flow and function in conscious dogs. Circ. Res. 47:201-207.

33. Wyatt, H. L., J. S. Forrester, J. V. Tyberg, S. Goldner, S. E. Logan, W. W. Parmley, and H. J. C. Swan. 1975. The effect of graded reductions in regional coronary perfusion on regional and total cardiac function. Am. J. Cardiol. 36:185-192.

34. Weintraub, W., S. Hattori, J. B. Agarwal, M. M. Bodenheimer, V. S. Banka, and R. H. Helfant. 1981. The relationship between myocardial blood flow and contraction by myocardial layer in the canine left ventricle during ischemia. Circ. Res. 48:430-438.

35. Cohen, M. V., and E. S. Kirk. 1973. Differential response of large and small coronary arteries to nitroglycerin and angiotensin: autoregulation and tachyphylaxis. Circ. Res. 33:445-453.

36. Kelley, K. O., and E. O. Feigl. 1978. Segmental alpha-receptor-mediated vasoconstriction in the canine coronary circulation. Circ. Res. 43:908-917.

37. Winbury, M. M., and Y. Abiko. 1979. Ischemic myocardium and antianginal drugs. Perspect. Cardiovasc. Res. 3:1-112. 